\title{
A abordagem dialética para a inovação no Design: o processo dialógico na transformação de artefatos
}

\section{Dialectic approach to innovation in Design: the dialogic process in the artifacts transformation}

\author{
Alberthy Alysson Coelho Bernardo, Universidade Federal de Campina Grande \\ alberthyacb@gmail.com
}

Wellington Gomes de Medeiros, Universidade Federal de Campina Grande

wellingtondemedeiros@gmail.com

\section{Resumo}

Este artigo relata investigação acerca da relação entre Design e dialética fundamentada na tríade hegeliana (tese-antítese-síntese). O estudo parte do pressuposto de que os princípios dialéticos podem ser aplicados ao Design em pelo menos duas instâncias: primeiro, no processo de concepção de ideias, em que a tríade sistematiza a geração de novos conceitos a partir da negação dialética; segundo, na análise das transformações dos artefatos em uma perspectiva histórica. As conclusões da pesquisa indicam que é possível correlacionar as leis da teoria dialética com o processo de design, contribuindo para a interpretação da inovação radical, incremental e do design dominante com base em duas dimensões: macro e microprocessos..

Palavras-chave: Dialética, Design, Inovação, Processo

\begin{abstract}
In this article the relationship between Design and the Hegelian system of dialectics (thesisantithesis-synthesis) is investigated. This study considers possible to apply the dialectical principles to at least two instances: first, in the ideation process by which new concepts are systematized from the dialectical negation. Second, in the analysis of the artifact transformations from a historical perspective. Findings indicate the feasibility of correlation between the laws of dialectical theory with the design process. Therefore, it can contribute to the interpretation of radical and incremental innovations, and the identification of the dominant design, based on two dimensions: macro and microprocesses.
\end{abstract}

Keywords: Dialectic, Design, Innovation, Process 


\section{Introdução}

A possibilidade de transformar os diversos contextos às mais variadas necessidades das pessoas tem sido continuamente ampliada. Entretanto, foi a partir do século XVIII, com o advento da produção em série proporcionada pela industrialização, que houve uma crescente oferta de produtos para satisfazer as necessidades práticas e demais expectativas dos consumidores (HESKETT, 2001). Concomitante à Revolução Industrial na Inglaterra, por volta de 1750, surge a figura do designer industrial, cujas atribuições têm sido objeto de avaliações e críticas por parte de teóricos e historiadores que buscam definir sua caracterização e compreender sua história (CARDOSO, 2016; FORTY, 2007; BURDEK, 2008; HESKETT, 2001; LOBACH, 2001).

Entre a definição do Design enquanto disciplina e da atuação do designer no campo profissional, podemos discutir que também é necessário investigar como ocorre o processo de inovação dos artefatos, uma vez que, ao entender os diversos fatores que favorecem a evolução das coisas criadas pelo homem, talvez possamos compreender melhor as mudanças nas relações sociais que fundamentam a criação e a oferta de novos produtos.

A sociedade contemporânea tem sido caracterizada por relações complexas, líquidas e em trânsito, conduzindo os indivíduos para um campo de reflexão fundado em um espaço globalizado com conexões dinâmicas e de rápido compartilhamento de informações (CARDOSO, 2016; BAUMAM 2009; ARANTES, 2008). Neste contexto, tanto as relações sociais quanto as relações entre as pessoas e os objetos são redefinidas em um processo cotidiano de fragmentação e reconfiguração a partir das percepções acerca dos elementos externos ao próprio ser social.

$\mathrm{Na}$ medida em que as relações entre as pessoas e com o mundo têm se tornado cada vez mais complexas, os designers são constantemente desafiados a enfrentar e resolver novas demandas. Tipos diversos de problemas requerem ampliação de conhecimento. Consequentemente, a interdisciplinaridade se tornou fundamental para a pesquisa no processo de Design, estabelecendo diálogos com disciplinas distintas de sua natureza (MURATOVSKI, 2015; CARDOSO, 2016). Neste sentido, Beckett (2017) afirma que o melhor caminho para pensar a lógica dos problemas é aquele que segue uma abordagem dialética, fazendo referência a Friedrich Hegel, mais especificamente ao sistema dialético da lógica.

Seguindo esta perspectiva, este estudo explora a aproximação entre design e dialética a fim de discutir o processo de inovação nos artefatos, uma vez que, tal como a dialética, a inovação não é um fenômeno estático, pois lida com constantes transformações. Considere-se ainda a concepção de que a fundamentação teórica do Design está alicerçada em campos das ciências clássicas como a Filosofia e as Artes, que originalmente tinham outro objeto de estudo (COUTO, et al., 2014; MURATOVSKI, 2015). Deste modo, o estudo do Design segundo preceitos filosóficos para investigar a inovação enquanto fenômeno pode gerar contribuições para discussões sobre a teoria do Design.

\section{Considerações sobre inovação em Design}

Ao interagirem com objetos e produtos na execução de tarefas cotidianas, as pessoas observam suas características, tecem críticas e propõem soluções inovadoras. Essas práticas criativas dão 
forma à grande variedade de objetos criados pela humanidade, desde combinações simples a soluções complexas (PETROSKI, 2007; ARKIPOV, 2011; NORMAN, 2006). Petroski (2007) afirma que os objetos são modelados por meio das experiências dos usuários nos contextos social, cultural e tecnológico, e que o estudo da evolução das coisas pode ser um ponto de partida para compreender a natureza do Design e da inovação.

O termo inovação surgiu a partir dos trabalhos do economista austríaco Joseph Schumpeter que elaborou a teoria do desenvolvimento econômico, definindo que uma inovação se estabelece quando ocorre uma transação comercial e a consequente geração de riqueza (SCHUMPETER, 1998). Seu argumento principal é de que o desenvolvimento econômico é conduzido pela inovação por meio de um processo dinâmico em que as novas tecnologias substituem as antigas, em um processo por ele denominado de "destruição criadora" (FINEP, 2005; TIDD, 2005). Tidd (2005) explica que o conceito de inovação está conectado a fatores econômicos empresariais e ao potencial competitivo, uma vez que, conforme a ideia de Schumpeter, os empresários usam a inovação tecnológica para obter vantagem estratégica, explorando habilidades tecnológicas para criar e disponibilizar novidades. Neste sentido, fica evidente que a origem do conceito de inovação está ligada ao valor comercial das empresas baseado na geração de lucro, diferenciação de mercado, estratégia competitiva e capacidade de gerar mudanças através de novos produtos no mercado (SANTOS, et al., 2011; PINHEIRO \& MERINO, 2015).

Ao longo das últimas décadas tem ocorrido uma tentativa de padronização de conceitos e metodologias, além de determinar indicadores para a classificação de inovação nos países industrializados, como por exemplo: o Manual de Oslo (FINEP, 2005); classificação a partir do grau de novidade (SCHUMPETER, 1998; CRUICKSHANK, 2010; TIDD, 2005), descrita como inovações incrementais ou radicais; definição dos tipos de inovações geradas: inovações de produtos, processo, posicionamento; paradigma; marketing; organizacional (FINEP, 2005; TIDD, 2005); por meio do posicionamento histórico (RICCINI, 2001; PINHEIRO et al. 2015; GONDIN, 2008); quanto ao tipo de estrutura, inovação aberta ou fechada (CHESBROUGH, 2003); e quanto ao impacto social e sustentável da inovação (MANZINI \& VEZZOLI, 2016). Esta última se diferencia do conceito de inovação voltada apenas ao mundo dos negócios, estando mais próxima de uma perspectiva de colaboração e transformação da comunidade.

A despeito da crescente inserção da inovação em diversos setores da sociedade, é importante destacar que, embora seja observada uma tendência para relações mais colaborativas e fora da área econômica, a aproximação da inovação com a disciplina do Design é recente. Somente nas últimas décadas houve uma mudança de foco quanto à dinâmica social da inovação, abrindo novas perspectivas para várias disciplinas - incluindo o Design - que pesquisam a inovação como um processo social (RICCINI, 2001).

A conexão entre Design e inovação tem provocado crescente interesse como objeto de pesquisa, sobretudo na era digital. No entanto, apesar de ser possível identificar pontos em comum entre as duas disciplinas, como por exemplo: a intenção de propor algo novo; estabelecer uma relação competitiva no mercado; atuar no campo dos produtos, serviços e processo; e intermediar a relação das novas tecnologias e as necessidades dos usuários (PINHEIRO, et al., 2015), a definição de inovação em Design permanece uma tarefa complexa (RICCINI, 2001; CRUICKSHANK, 2010; PINHEIRO, et al., 2015; MORTATI, 2015). 
Cruickshank (2010) comenta que, embora as duas áreas pareçam coincidentes em sua natureza, limitações de diálogo entre elas geram ruídos que desfavorecem principalmente o Design, sobretudo porque envolve aspectos não quantificáveis e subjetivos. A natureza qualitativa do Design parece estabelecer barreiras que dificultam a compreensão acerca de seu valor para a inovação, sobretudo porque a gestão da inovação é compartilhada com outros setores como Engenharia e Marketing, para os quais, na perspectiva financeira, o produto só é considerado inovação quando gera lucro (RAMPINO, 2011). Neste contexto, mensurar o valor subjetivo do Design tem sido o principal desafio, já que a inovação tem origem na economia e tem por base a metrificação quantitativa de resultados na geração de lucros.

Do ponto de vista da discussão teórica, Lambert e Flood (2017) resumem as principais ideias sobre o papel do Design na inovação assim identificando-as: Science of the Artificial; Design Thinking; Design Driven Innovation; Concept-Knowledge Theory; Design Practice; Service Design and Innovation; Social Innovation. Cada teoria define uma perspectiva particular para o processo de inovação. Assim, a relação entre Design e inovação pode ser caracterizada por uma multiplicidade de pontos de vista, expressas por diferentes autores que tendem a se contrapor, embora tratem de abordagens complementares.

\section{Considerações sobre o pensamento dialético}

A dialética surgiu na Grécia antiga (aprox. 540-480 a.C) como a arte do diálogo, posteriormente evoluindo para a demonstração de uma tese por meio de argumentos em uma discussão. Um dos pensadores mais radicais da Grécia antiga foi o filósofo Heráclito de Éfeso, dito o Pai da Dialética (KONDER, 2008).

Uma parábola atribuída a Heráclito narra que um homem não pode banhar-se duas vezes no mesmo rio porque na segunda vez o rio terá mudado devido ao fluxo contínuo da água. Do mesmo modo, o homem também não será o mesmo. Na visão de Heráclito, tudo está em constante mudança, e o conflito é transformador de todas as coisas. Porém, os gregos acharam os questionamentos de Heráclito muito obscuros e perturbadores, preferindo o discurso metafísico. Por estas razões o conceito de dialética foi preterido por um longo período, mas permaneceu ativo entre alguns filósofos como Montaigne, Denis Diderot e Rousseau, ressurgindo como ideologia no modernismo expresso no idealismo de Friedrich Hegel (KONDER, 2008).

Hegel sistematizou a lógica dialética na tríade tese/antítese/síntese, que posteriormente foi reformulada por Karl Max e Friedrich Engels no materialismo dialético (CASSETI, 2009). A partir da ideologia de Hegel, Friedrich Engels, na obra 'Dialética da Natureza', estabelece as leis gerais da dialética fundamentadas no princípio da contradição da matéria:

1. Lei da passagem da quantidade à qualidade. Refere-se à ideia de que as coisas não mudam sempre no mesmo ritmo; o processo de transformação por meio do qual elas existem passa por períodos lentos - nos quais se sucedem pequenas alterações quantitativas - e por períodos de aceleração - que precipitam alterações qualitativas. 
2. Lei da interpretação dos contrários. Ressalta a inexistência de fenômenos isolados na natureza. Os diversos aspectos da realidade se entrelaçam e, em diferentes níveis, dependem uns dos outros, de modo que as coisas não podem ser compreendidas isoladamente.

3. Lei da negação da negação. Resgata o idealismo hegeliano e determina que a realidade não se restringe à mera repetição da tese e da antítese, entre afirmações e negações, mas que na verdade é a junção de ambas que, uma vez superadas, geram a síntese.

Com base nessas premissas, a dialética se tornou um método influente na compreensão da natureza enquanto fenômeno dinâmico no qual as coisas estão em constante mudança (GALANTE, 2018). Neste sentido, e considerando a dinâmica do processo de investigação, Lakatos e Marconi (2007) afirmam que "nenhuma coisa está 'acabada', encontrando-se sempre em vias de se transformar, desenvolver; o fim de um processo é sempre o começo de outro" (LAKATOS \& MARCONI, 2003, p. 101).

Para Hegel, a superação dialética "é simultaneamente a negação de uma determinada realidade, a conservação de algo de essencial que existe nessa realidade negada e a elevação dela a um nível superior" (KONDER, 2008, p. 25). Portanto, a lógica do pensamento hegeliano está conectada a um processo dialético que se desloca desde a mais pura abstração até o mais concreto que é a Ideia Absoluta, que se desdobra em uma estrutura em movimento (NICOLAU, 2010). Seguindo esta perspectiva, Galante (2018) destaca a tensão que existe entre oposições, na qual o processo de tese, antítese e síntese se constrói (Figura 1).

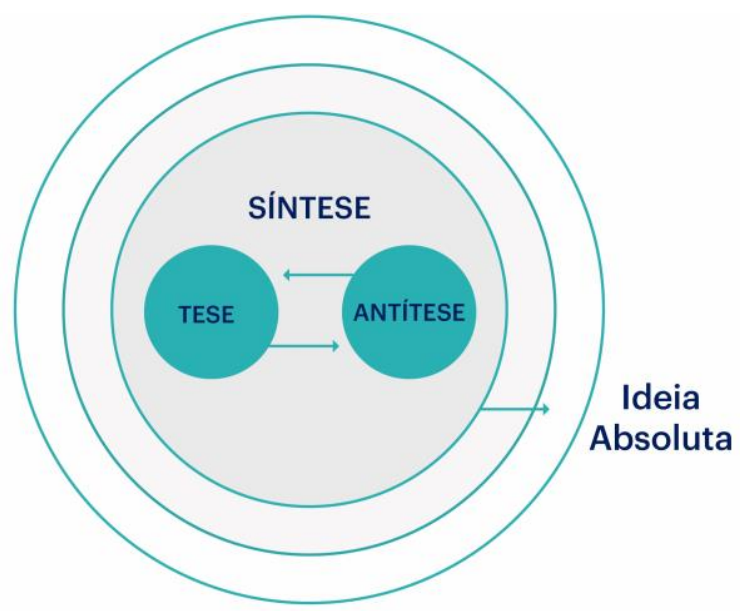

Figura 1: A Ideia Absoluta na tríade de Hegel. Fonte: adaptado de Galante (2018)

A Figura 1 resume o conceito estabelecido pela tríade hegeliana: (a) as limitações da TESE expressas na argumentação fixa geram seu oposto: a ANTÍTESE; (b) a tensão estre estas duas partes instaura outro conceito: a SÍNTESE, que abrange tanto a tese quanto a antítese; (c) a dinâmica de interdependência entre as três partes fundamenta a máxima hegeliana de que nenhuma coisa surge do nada (GALANTE, 2018).

Em resumo, de acordo com Hegel, a lógica apresentaria três estágios: Fixidez, o primeiro momento da forma estável, é a ideia entendida como a verdade a ser contestada; Dialética, é o momento contrário em que as limitações da fixidez se tornam aparentes, descrito como um 
processo de negação para gerar seu oposto ou instabilidade; e por último, a Especulação, que reconhece a unidade inerente às duas determinações anteriores e as unifica.

\section{Dialética aplicada ao Design}

A relação entre Design e dialética é explorada em "The Dialectical Approach To System Design" (1995), de Lars Taxén. O autor utiliza a abordagem dialética para pensar sistemas de design no ambiente de telecomunicações, associado ao princípio da interdependência das partes. $\mathrm{O}$ autor argumenta que uma perspectiva reducionista cartesiana nem sempre consegue lidar com sistemas complexos. A dialética se apresentaria como alternativa para compreender a totalidade dos sistemas que são complexos por serem multidimensionais, com vários fenômenos em níveis variados interagindo no mesmo ambiente. Assim, não seria possível compreender o Design se não por uma teia de fenômenos e interações. Taxén (1995) conclui que a abordagem dialética para o design de sistemas complexos torna possível novas soluções para problemas já identificados ao enfatizar dois aspectos: a interação dinâmica em um processo adaptável; e a influência mútua de todos os requisitos. Portanto, o pressuposto dialético determinaria que todas as partes são interdependentes para a formação do todo.

Em 'Dialectics of design: how ideas of 'good design' change”, Tomes e Armstrong (2010), utilizam um procedimento lógico para analisar estilos dos objetos domésticos em três movimentos da história do Design: Arts and Crafts; Art Nouveau; e Modernismo. Os autores destacam a existência de uma tensão entre a disponibilidade indiscriminada de produtos para os usuários, a conformidade de ideias do designer, e as exigências comerciais das empresas. Eles concluem que cada escola de Design, em seu tempo, determina seu ideal ao se opor às definições anteriores. Logo, para compreender os movimentos históricos do Design, os autores aplicam a lei do embate entre contrários, e a contraposição de ideias entre as escolas determinaria o movimento dialético histórico.

Não obstante, os trabalhos de Texén (1995) e Tomes \& Armstrong (2010) abordem o pensamento dialético em uma perspectiva sistemática e histórica, ainda há pouquíssimos trabalhos científicos publicados sobre o assunto. Por vezes, o termo dialética é apresentado como sinônimo de contraposição entre duas ideias, mas sem contemplar a totalidade de sua natureza e conceito.

As publicações levantadas nesta pesquisa nos últimos três anos que discutem especificamente o Design a partir da tríade hegeliana são relativamente recentes. No artigo "The Logic of the Design Problem: A Dialectical Approach", Beckett (2017) argumenta que as teorias mais recentes sobre solução de problemas em design têm abandonado a ideia 'problema versus solução' como fases em um processo linear e adotado, ao invés, o sentido de 'desenvolvimento simultâneo'. Ou seja, a busca pela compreensão do problema de projeto seria concomitante à descoberta de sua solução. O problema do paradoxo entre problema e solução reside na ideia de autonomia de um em relação à outra e da perspectiva cronológica de que a solução só acontece depois do problema. A proposta seria, portanto, considerar a relação problema-solução como partes complementares e sincrônicas.

A abordagem dialética permite entender o Design como atividade cognitiva e lógica de pensamento. Beckett (2017) argumenta que a análise triádica [tese-antítese-síntese] possibilita 
compreender como o designer intervém na realidade quando, ao trabalhar com o problema, efetua transformações em seu contexto. Na lógica dialética o progresso das ideias e da história seguem a oposição de um conceito - a tese - ao seu equivalente lógico - a antítese - que eventualmente se resolve na síntese. Embora possam parecer três conceitos distintos, emergem simultaneamente pois ao postular seu conteúdo afirmativo, a tese necessariamente instaura sua negação (BECKETT, 2017).

Galante (2018) exemplifica o conceito de autonegação do seguinte modo: quando se afirma que um carro é vermelho, automaticamente, também é afirmado que não é nenhuma outra cor. Esta lógica, quando aplicado ao Design, possibilita infinitos modos de solucionar um problema, considerando desde escolhas estéticas, funcionais e materiais, assim como as escolhas do cliente.

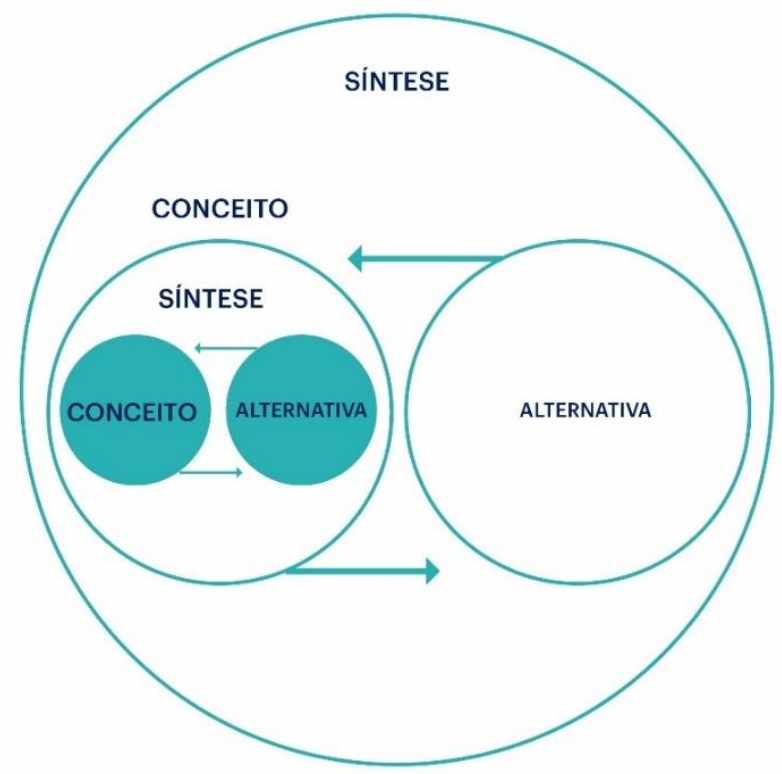

Figura 2: O processo dialético no Design. Fonte: Adaptado de Galante (2018)

Tanto Galante (2018) quanto Beckett (2017) aplicam os conceitos da dialética no Design enquanto processo de concepção e da ideia a partir do confronto de alternativas conceituais (Figura 2). Neste sentido, a antítese é a chave para que aconteça o confronto de ideias no paradigma problema - solução.

Deste modo, o processo de concepção de ideias no Design pode ser entendido segundo sua natureza dialética a partir da progressão de conceitos simples para conceitos universais. É possível afirmar que nunca haverá uma solução de Design como ideal absoluto, como a única e melhor solução, uma vez que o sentido de ideia absoluta só existe por um curto prazo, até ser questionada novamente.

\section{A inovação no Design como um processo dialético}

A filosofia hegeliana se propõe ao estudo da ideia desenvolvida em movimentos, caracterizada por uma sucessão de momentos (NICOLAU, 2010), em que os acontecimentos são 
interdependentes (GALANTE, 2018; LAKATOS \& MARCONI, 2003). De maneira análoga, no Design, projetar não se trata de propor algo sem conexão com o que já existe, porque isso seria pensar que quem está criando não tem repertório e nem recebe influência do seu entorno. Na verdade, de forma natural, porém nem sempre perceptível, o novo surge do pensamento sobre o existente, uma vez que referências pessoais e experiência de vida emergem no ato da criação, como destaca Aloísio Magalhães:

No processo de evolução de uma cultura, nada existe propriamente de 'novo'. O 'novo' é apenas uma forma transformada do passado, enriquecida na continuidade do processo, ou novamente revelada, de um repertório latente. $\mathrm{Na}$ verdade, os elementos são sempre os mesmos: apenas a visão pode ser enriquecida por novas incidências de luz nas diversas faces do mesmo cristal. (ALOISIO MAGALHÃES in LEITE (org.), 2003, p. 21-22)

Neste sentido, Verganti e Norman (2014) argumentam ser impossível gerar algo completamente novo, desconexo do que preexiste. Todas as ideias têm predecessores e, portanto, são baseadas em trabalhos anteriores, às vezes diferenciando-se pelo refinamento ou pela combinação de várias ideias preexistentes. Neste caso, o objeto referencial é um design dominante, ou seja, um arquétipo de produto específico que se tornou padrão para o mercado (ABERNATHY \& UTTERBACK (1978). Uma vez que este produto foi estabelecido, inovações incrementais baseadas neste modelo surgem no mercado fazendo surgir produtos semelhantes, até surgir um novo design dominante (RAMPINO, 2011).

De modo semelhante, Tidd (2005) relata que, quando um empreendedor lança um novo produto, seus concorrentes logo tentarão imitá-lo. Neste momento emergem outras inovações e o resultante de todas essas ideias é a quebra do monopólio do empreendedor, e quando se atinge o equilíbrio, o ciclo se repete. Schumpeter descreve esse processo como "destruição criativa" (TIDD, 2005; PINHEIRO \& MERINO, 2015; FIEP, 2005) onde há uma constante pesquisa para criar algo novo que destrói simultaneamente as regras antigas e estabelece as novas (TIDD, 2005).

Verganti e Norman (2014) apresentam o hill-climbing paradigm da inovação incremental e radical (Figura 3):

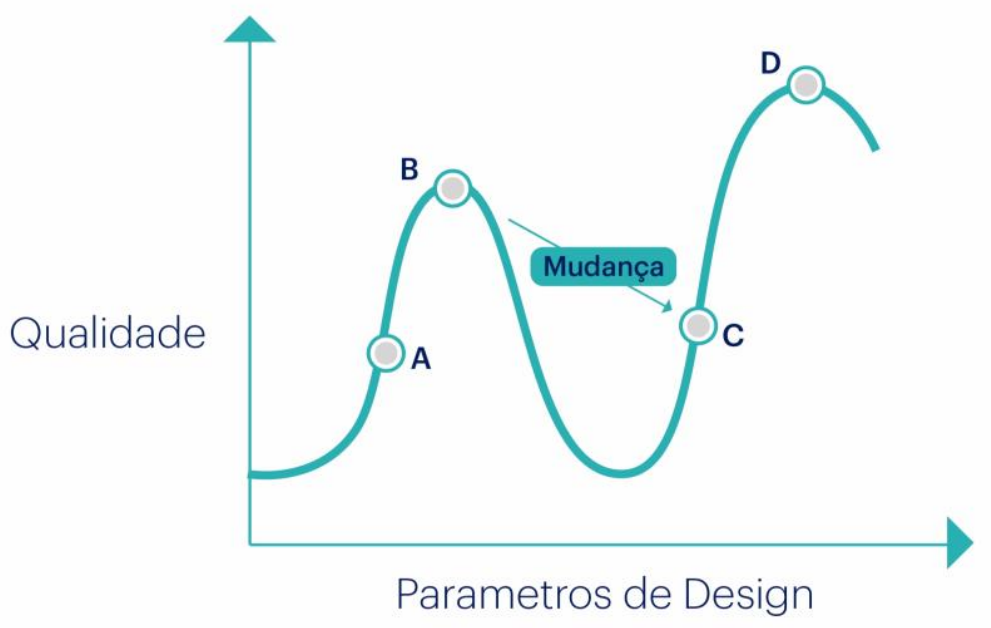

Figura 3: The hill-climbing paradigm applied to incremental and radical innovation. Fonte: adaptado de Verganti e Norman (2014) 
No esquema (Figura 3) podemos ver que um novo produto (A) é lançado no mercado. No decorrer do tempo, pequenas mudanças são acrescentadas, e, a partir de inovações incrementais, seu limite máximo de qualidade é atingido (B). A fim de avançar para um novo estágio, é preciso uma inovação radical, seja pela tecnologia, seja pelo significado do produto para os usuários $(\mathrm{C})$. Finalmente, o produto alcança o nível mais alto de transformação (D). Assim, o produto percorre um fluxo padrão de inovação. Neste caso, a dominância seriam os pontos $\mathrm{A}$ e C que servem de âncora para as inovações incrementais.

A literatura citada neste artigo trata da representação dinâmica entre dois opostos e do conceito de "destruição criadora" como próprios da dialética aplicada em um ciclo infinito. Portanto, a dialética não só pode contribuir para entender o conflito entre problema/solução, mas também compreender o processo de inovação dos artefatos (Figura 4).

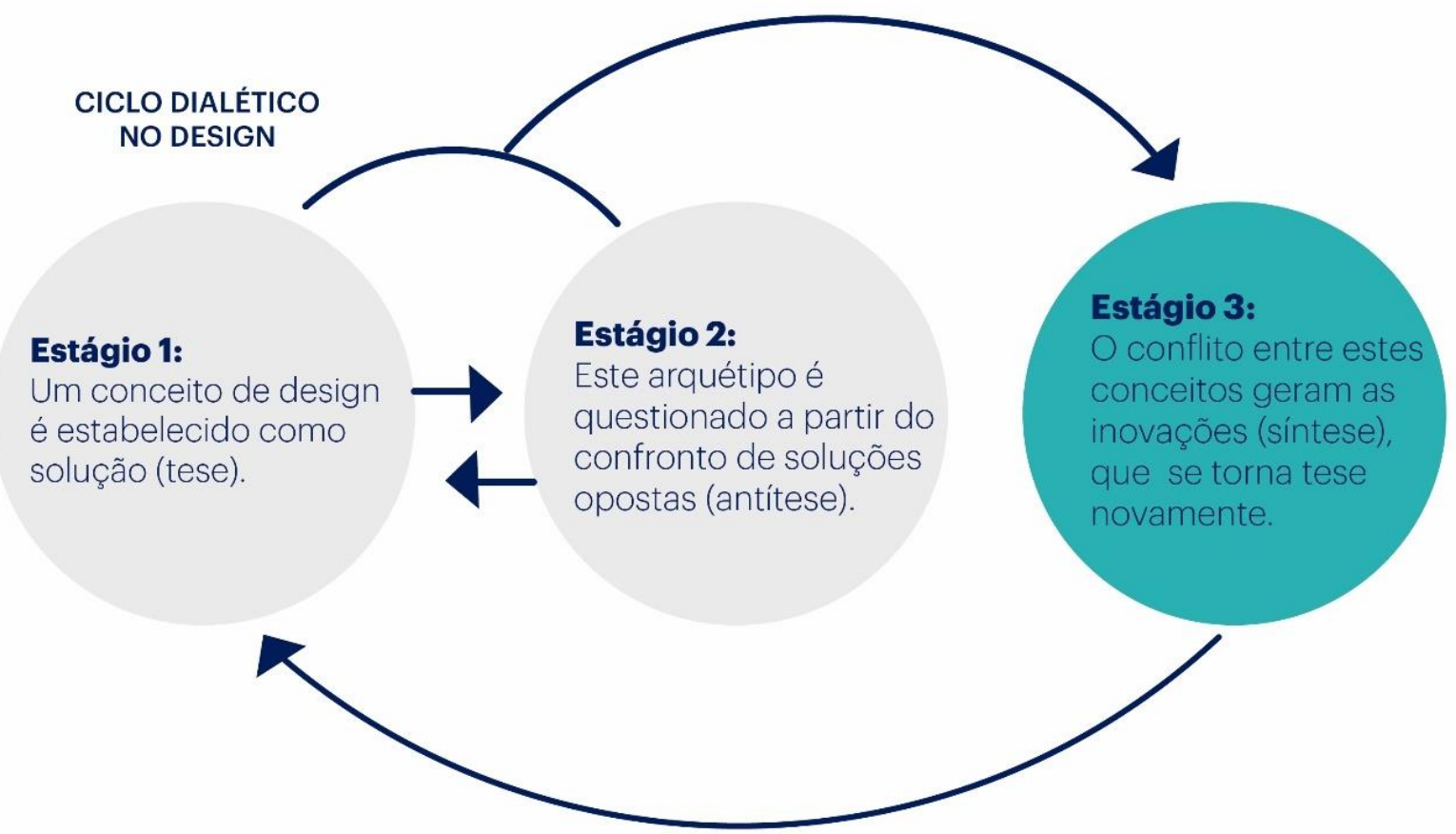

Figura 4: A inovação no Design como um processo dialético. Fonte: autoria própria (2019)

Assim, o processo de inovação seria o resultante da tese - configuração existente - versus a antítese - observação e questionamento sobre o objeto - para gerar a síntese - proposta inovadora. O design dominante (tese/fixidez) se torna questionável (negações) e esse conflito serve de base para gerar algo novo, que assume a posição de nova tese, recriando o ciclo.

Neste contexto, a dialética da inovação no Design, na perspectiva da análise dos artefatos, pode ser expressa de dois modos. No primeiro modo, quando identificamos o design dominante inicial e o seu sucessor, se tratando das modificações radicais da tipologia do produto, seja em 
aspectos formais, tecnológicos e de significado, que denominamos como 'macroprocesso dialético'.

No macroprocesso dialético encontramos a inovação radical a partir do design dominante, como por exemplo, no relógio de cada época (Figura 5).

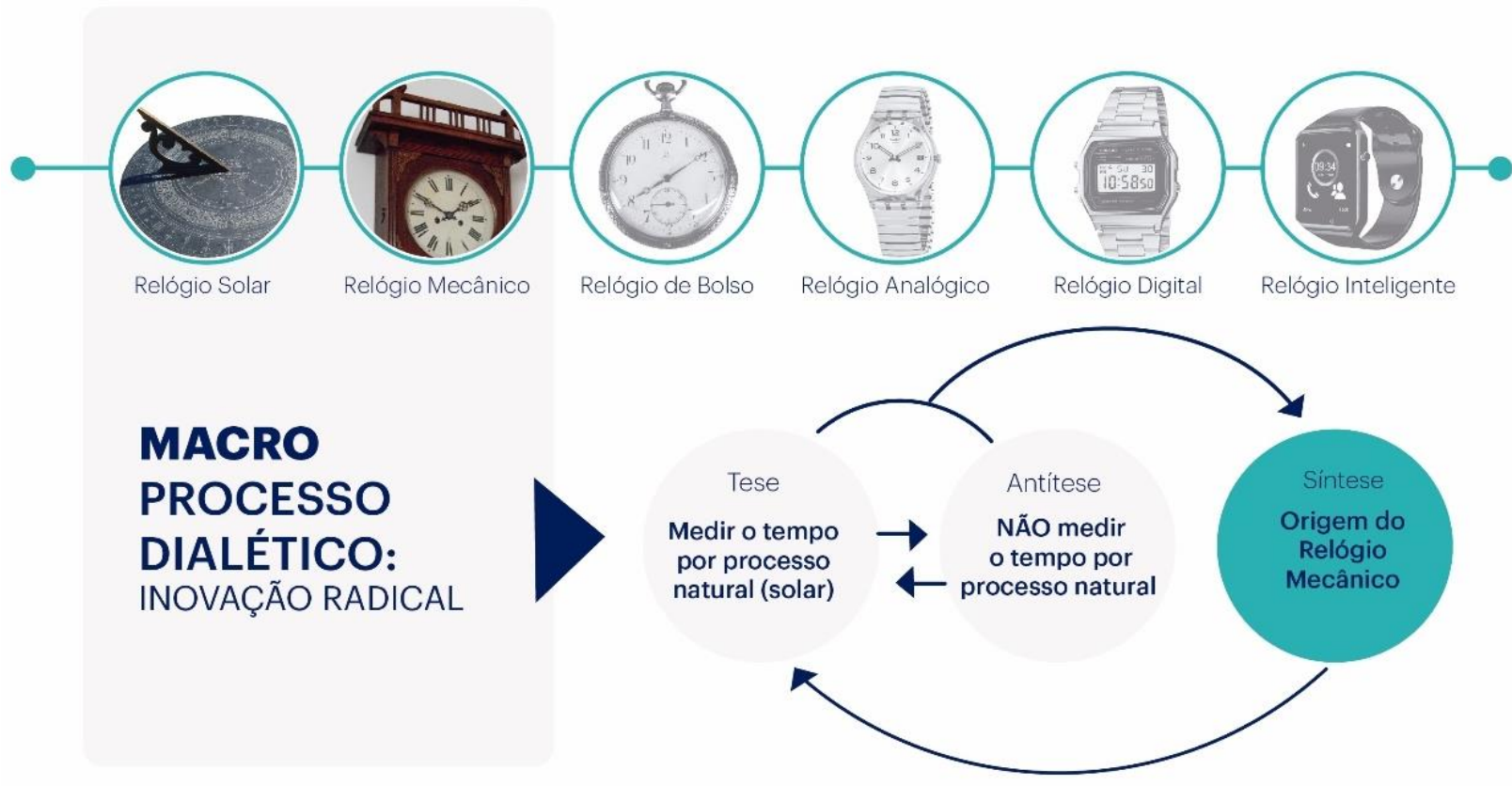

Figura 5: Macroprocesso dialético - inovação radical. Fonte: autoria própria (2019)

Durante o processo dialético dizemos que cada modelo é uma tese que em algum momento já foi o resultado de um questionamento. Ou seja, o relógio mecânico foi uma síntese de uma tensão dialética que questionava o relógio solar. Ao mesmo tempo, o próprio relógio mecânico, assumindo a posição de design dominante, foi deslocado para a condição de negação a fim de ceder espaço ao seu sucessor.

No segundo modo, denominamos de 'microprocesso dialético' os eventos que acontecem na interseção de dois dominantes. Sabemos que a inovação radical tem um ciclo mais longo e que, até que um novo design dominante surja, requer muito tempo de experimentação.

Assim, o microprocesso dialético acontece na interseção entre dois pontos do macroprocesso de inovação. No caso ilustrado (Figura 6), na passagem temporal entre o relógio analógico e o relógio digital surgem várias possibilidades de inovações incrementais a fim de mitigar riscos e custos, e atender novas demandas do mercado e de público. 

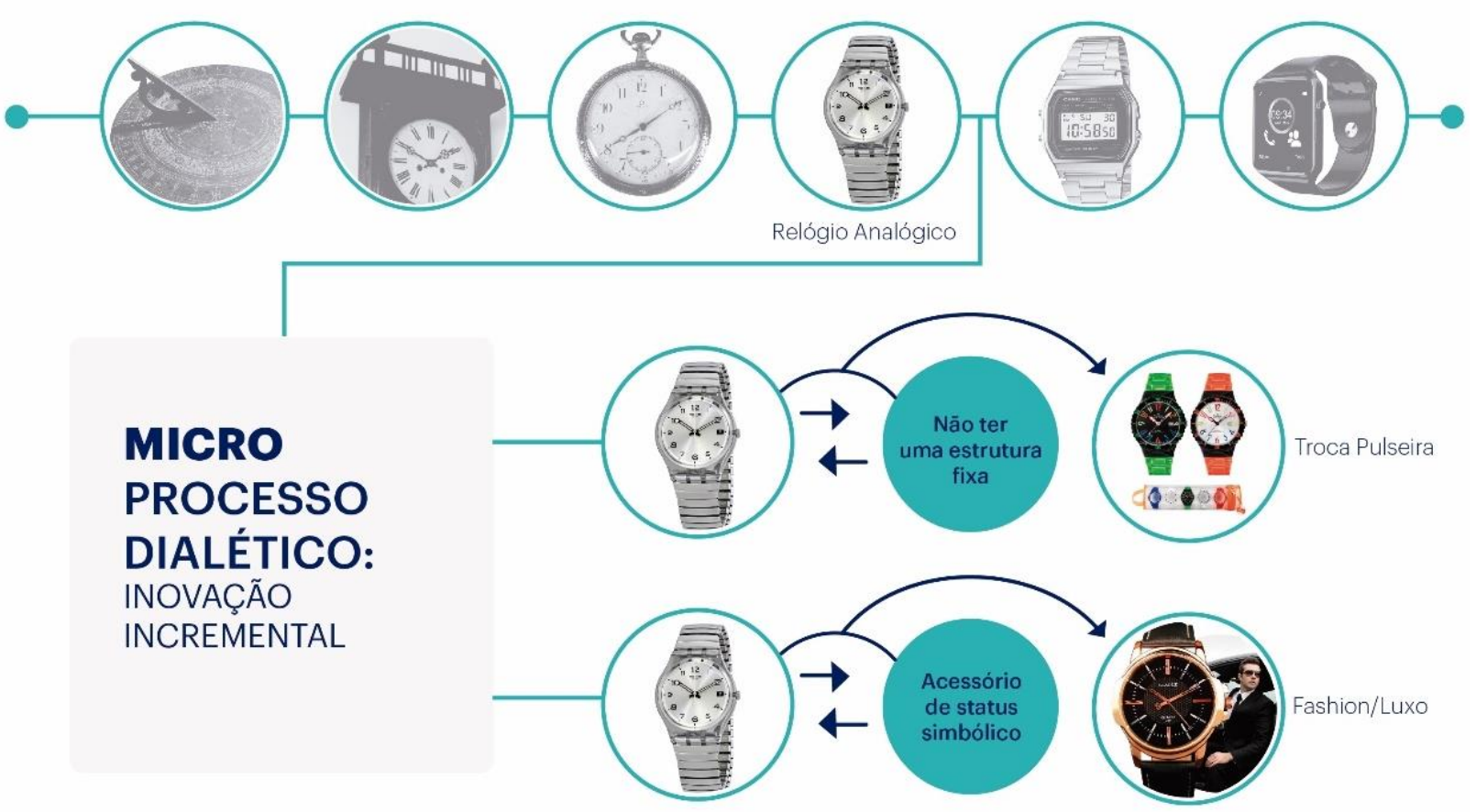

Figura 6: Microprocesso dialético - inovação incremental. Fonte: autores (2019)

Por fim, o estudo de cada contexto histórico-social possibilita a compreensão de como os produtos, a partir da interdependência com o usuário, reestruturam as relações sociais, se transformam ao longo do tempo e geram novos significados. Assim, podemos correlacionar as leis da dialética com o Design do seguinte modo:

\section{LEI}
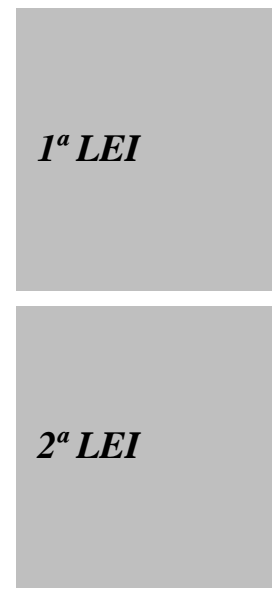

$3^{a}$ LEI

\section{DIALÉTICA}

Passagem da quantidade à qualidade

Interpenetração dos contrários

Negação da negação

\section{DESIGN}

Tudo está sujeito à mudança ao longo do tempo, desde a transformação tipológica do objeto até os significados a ele associados. Objetos podem se transformar a partir de inovações incrementais mais lentas (quantitativa) ou apresentar grandes saltos de inovações radicais (qualitativa).

As necessidades e desejos entre usuário e objeto são construídas de modo dinâmico a partir de fenômenos interligados. Cada parte tem seu papel no todo e a inovação é influenciada pelo contexto, incluindo a relação de tempo e espaço.

A definição do problema gera simultaneamente diversas possibilidades solucionadoras como alternativas contrárias ao problema. Todo arquétipo de design poderá ser questionado.

Quadro 1: Leis da dialética aplicada ao Design. Fonte: autores (2020) 
Por fim, deduzindo que o impulso criativo sempre esteve presente, é possível que o que temos feito ao longo da história tem sido justificar a criação das coisas: produzindo bens para troca ou subsistência; criando artefatos para contar nossa história; fabricar armamentos para defesa; gerar produtos para atender às necessidades dos usuários e do mercado; ou produzir material sustentável e de impacto social. Notamos que o Design tem buscado compreender a relação entre as pessoas e os objetos a partir de dicotomias, como por exemplo: problema/solução; objetividade/subjetividade; razão/emoção; analógico/digital; e tangível/intangível.

O reconhecimento do ciclo dialético desconstrói a consciência de que já teríamos criado absolutamente tudo. A lógica dialética ensina que, à medida que nos transformamos internamente e socialmente, acabamos por modificar o meio em que vivemos, no mesmo instante em que somos modificados pelo meio. Em outras palavras, as pessoas mudam a natureza por meio da intervenção e da criação dos artefatos, ao passo que a natureza modifica as pessoas, provocando uma relação cíclica dialética de ação e reação.

\section{Conclusão}

Se por um lado a relação entre Design e inovação ainda está em processo de estruturação, a conexão com o campo da dialética filosófica como forma de questionar e explicar essa relação ainda é incipiente. Neste sentido, no que tange a dialética, a literatura do Design, usualmente, utiliza o termo no sentido de dicotomia ou tem privilegiado o estágio de concepção em detrimento da ideia de evolução dinâmica e cíclica entre problema e solução.

Por outro lado, muitos dos estudos em inovação se concentram no resultado e seus efeitos, e não sobre o processo. Este artigo se propôs a ampliar e discutir a relação entre Design e dialética, sobretudo, a partir da estruturação da inovação como um processo dinâmico.

Podemos concluir que os princípios dialéticos podem ser aplicados ao Design em pelo menos duas instâncias. Primeiro, entendendo o Design como uma atividade lógica de pensamento, no processo de concepção de ideias, em que a tríade tese-antítese-síntese sistematiza a geração de novos conceitos, a partir da negação dialética. Segundo, utilizando a dialética para analisar as transformações dos artefatos em uma perspectiva histórica. É através da transformação que percebemos a evolução dos objetos. Essas mudanças podem ocorrer no nível da inovação incremental, analisada através dos microprocessos dialéticos, ou podem gerar mudanças no nível da inovação radical nos macroprocessos. Portanto, concluímos que é possível utilizar a abordagem dialética para investigar o processo de inovação dos artefatos.

Por fim, há poucas pesquisas explorando a conexão do Design com o pensamento dialético, e por esta razão, esta questão se apresenta como um campo aberto para a exploração teórica e com muitas possibilidades para gerar novas discussões para a teoria do Design.

\section{Referências}

ABERNATHY, W. J., \& UTTERBACK, J. M. Patterns of innovation in industry. Technology Review, 80(7), 40-47, 1978. 
ARANTES, P. Tudo que é sólido derrete: da estética da forma à estética do fluxo. Em: Estéticas Tecnológicas: novos modos de sentir. São Paulo: Educ, pp. 21-28, 2008.

ARKHIPOV, V. "Functining Forms / Anti-Design." Em Design Antropology: object culture in the 21 century, por Alison J. CLARKE, 169-183. New York: Springer Wien, 2011.

BAUMAN, Z. Modernidade Líquida. 1ª Rio de Janeiro: Jorge Zahar, 2001.

BECKETT, S. J. The Logic of the Design Problem: A Dialectical Approach. Design Issues 33, no $4^{\text {a }}$ Autumn, 2017.

BÜRDEK, B. E. História, teoria e prática do design de produtos. São Paulo: Blücher, 2006.

CARDOSO, R. Design para um mundo complexo. 2. São Paulo: Ubu Editora, 2016.

CASSETI, V. Contra a correnteza. Goiás, 2009.

CHESBROUGH, H. W. Open Innovation: The New Imperative for Creating and Profiting from Technology. Boston, Massachusetts: harvard business school press, 2003.

COUTO, R. M. S., FARBIARZ, J. L., NOVAIS, L. Gustavo Amarante Bonfin: uma coletânea. $1^{\text {a }}$. Rio de Janeiro: Rio Books, 2014.

CRUICKSHANK, L. The Innovation Dimension: Designing in a Broader Context. Design Issues 26, $\mathrm{n}^{\circ} 2$ Spring, 2010.

FINEP. Manual de Oslo: diretrizes para coleta e interpretação de dados sobre inovação. 3 . Tradução: Flávia Gouveia. DCOM/FINEP, 2005.

FORTY, A. Objetos de desejo: design e sociedade desde 1750. São Paulo: Cosac Naify, 2007.

GALANTE, V. Design e Dialética. Toronto, Ontario: OCAD University, 2018.

GONDIN, B. Innovation: the history of a category. Project on the Intellectual History of Innovation. Montreal, Canadá: Working Paper, 2008.

HESKETT, J. Industrial Design. 2 ${ }^{\text {a }}$. Singapura: Thames \& Hudson, 2001.

KONDER, L. O que é Dialética. 28 Primeiros Passos. São Paulo: Brasiliense, 2008.

LAKATOS, E. M., MARCONI, M. A. Fundamentos de metodologia científica. 5a. São Paulo: Atlas SA, 2003.

LAMBERT, R., FLOOD, R. Understanding design-intensive innovation: a literature review. Reino Unido: Design Consul, 2017.

LEITE, J. S. A herança do olhar - o design de Aloísio Magalhães. Rio de Janeiro: Senac Rio, 2003.

LÖBACH, B. Design Industrial: bases para a configuração de produtos industriais. São Paulo: Blücher, 2001.

MAZZINI, E. \& VEZZOLI, C. O Desenvolvimento de Produtos Sustentáveis: tradução de Astrid de Carvalho. 1. Ed. 4. Reimpr.- São Paulo: Editora da Universidade de São Paulo, 2016. 
MORTATI, M. A Framework for Design Innovation: Present and Future Discussions. Design Issues 31, nº 4 Autumn, 2015.

MURATOVSKI, G. Research for Designers: a guide to methods and practices. $1^{\circ}$. London: SAGE publications Ltd, 2016.

NICOLAU, M. F. A. A ciência da lógica no sistema hegeliano. Kínesis 2, nº 3, 2010.

NORMAN, D. A. O design do dia-a-dia. Tradução: Ana Deiró. Rio de Janeiro: Rocco, 2006.

PETROSKI, H. Evolução das Coisas Úteis: clipes, garfos, latas, zíperes e outros objetos do nosso cotidiano. Tradução: Carlos Irineu W. da Costa. Rio de Janeiro: Jorge Zahar, 2007.

PINHEIRO, I. R., MERINO, E. A. D. Os 4 vetores da inovação: Um quadro de referência para a gestão estratégica do design. Estudos em Design 23, $\mathrm{n}^{\circ} 2,2015$.

PINHEIRO, I. R., MERINO, E. A. D., GONTIJO, L. A. Sobre a definição de inovação em design: o uso da análise de redes para explorar conceitos complexos. Revista Brasileira de Design da Informação 12, no 3, 2015.

RAMPINO, L. The Innovation Pyramid: A Categorization of the Innovation Phenomenon in the Product-design Field. International Journal of Design 5, n ${ }^{\mathrm{o}}$ 1, 2011.

RICCINI, R. Innovation as a Field of Historical Knowledge for Industrial Design. Design Issues 17, nº 4 Autumn, 2001.

SANTOS, A. B. A., FAZION, C. B., MEROE, G. P. S. Inovação: um estudo sobre a evolução do conceito de Schumpeter. Caderno de Administração da FEA PUC/SP 5, n ${ }^{\circ} 1^{a}$, 2011.

SCHUMPETER, J. A teoria do desenvolvimento econômico. São Paulo: Nova Cultural, 1988.

TAXÉN, L. The Dialectical Approach to System Design. Austin, Texas: First World Conference on Integrated Design and Process Technology, 1995.

TIDD, J. Integrating Technological, Market and Organizational Change. $3^{\text {a }}$. Chichester: John Wiley \& Sons Ltd, 2005.

TOMES, A., ARMSTRONG, P. Dialectics of design: how ideias of 'good design' changeby. Prometheus $28, \mathrm{n}^{\circ} 1,2010$.

VERGANTI, R., NORMAN, D. A. Incremental and Radical Innovation: Design Research vs. Technology and Meaning Change. Design Issues 30, $\mathrm{n}^{\circ} 1$ Winter, 2014.

\section{Sobre os autores}

Alberthy Alysson Coelho Bernardo

Designer de produto com foco em UX/UI e design estratégico. Mestre em Design pela Universidade Federal de Campina Grande (2020), com ênfase no estudo da relação entre em Design e Inovação. Graduado em Design de Produto pela Universidade Federal do Cariri (2016), com período sanduíche na Università di Bologna - Itália;

ORCID: https://orcid.org/0000-0001-7533-0221 


\section{Wellington Gomes de Medeiros}

Possui PhD em Design pela Universidade de Staffordshire, Inglaterra (2007); Mestrado em Artes Visuais pela Universidade Federal do Rio Grande do Sul (1998); e Graduação em Desenho Industrial pela Universidade Federal da Paraíba (1988). Atualmente é professor adjunto no Curso de Desenho Industrial da Universidade Federal de Campina Grande.

ORCID: https://orcid.org/0000-0002-8931-5003 